\title{
Performance of Multimodel Schemes for Seasonal Precipitation over Indian Region
}

\author{
Vinay Kumar $\mathbb{D}^{1}$ and Tirthankar Ghosh ${ }^{2}$ \\ ${ }^{1}$ Department of Physical and Environmental Sciences, Texas A\&M University, Corpus Christi, TX 78412, USA \\ ${ }^{2}$ Department of Statistics, Visva Bharati University, Bolpur Santiniketan, West Bengal 731235, India \\ Correspondence should be addressed to Vinay Kumar; vinay.kumar@tamucc.edu
}

Received 5 July 2017; Revised 15 October 2017; Accepted 8 November 2017; Published 3 January 2018

Academic Editor: Takashi Mochizuki

Copyright (c) 2018 Vinay Kumar and Tirthankar Ghosh. This is an open access article distributed under the Creative Commons Attribution License, which permits unrestricted use, distribution, and reproduction in any medium, provided the original work is properly cited.

\begin{abstract}
This study uses downscaled rainfall datasets from 16 coupled climate models at high resolution of $25 \mathrm{~km}$ from 1987 to 2001 . The multimodel superensemble scheme is widely tested for rainfall forecast over mid-latitude, subtropical, and, especially, various regions of the monsoonal belt. A well-known statistical estimation theoretic approach, namely, Best Linear Unbiased Estimator (BLUE), is examined on 16 member models. The results are compared with superensemble methodology based on various skill scores. Results show that BLUE is providing promising forecasts. As far as comparative studies are concerned BLUE and superensemble schemes compete and show their importance from normal years to extreme rainfall years. BLUE methodology is capable of predicting draughts very well compared with other multimodel schemes. One basic advantage of BLUE is computationally less expensive than superensemble scheme. These statistical schemes like downscaling, BLUE, and superensemble can improve rainfall forecasts further, if a dense rain gauge data is provided.
\end{abstract}

\section{Introduction}

Several multimodel schemes are being listed in the literature of the climate and weather for rainfall prediction. These commonly used multimodel rainfall forecast schemes are ensemble scheme, biased removed ensemble mean, clustering techniques, and superensemble method. The superensemble scheme from Florida State University (FSU) is being tested since 1999 by various researchers [1-4]. Nowadays a good quality of rainfall dataset is available from satellites (e.g., Global Precipitation Measurement, GPM/Tropical Rainfall Measuring Mission, TRMM), reanalysis (e.g., MERRA), and rain gauge (e.g., APHRODITE) at high resolution. Somehow climate global models still have a coarse resolution of $100 \mathrm{~km}$. Such gap of resolution calls for downscaling of the climate global models. All the acronyms are mentioned in Acronyms for Models, Institutes, or Other Names.

Statistical downscaling procedures have been used to improve the horizontal resolution of the member models [49]. By doing so, the regional details of the dry and wet patches of rainfall bulge out. There are limitations of dynamical models and postprocessing statistical techniques in predicting seasonal rainfall $[1,10]$. The successes of statistical methods depend on the long-time series of data for training period to calculate better-quality coefficients. If the training datasets consist in many new information pieces on flood and drought events, then their obtained coefficients do better in forecast period. On the other hand, dynamical models have problems with their parametrization schemes and some simplification of various schemes used in them. In these models, systematic error grows with time. Worldwide more than 20 climate prediction centers are engaged in the monthly to seasonal predation with their home grown global models. Multimodel schemes were suggested to bring consensus forecast for a season [11-13].

India Meteorological Department has used statistical models and modified them over a period to provide an improved Indian summer monsoon rainfall prediction [1417]. Some of the limitations of statistical and dynamical models used for Indian rainfall prediction are noted by Nanjundiah [18] and Gadgil et al. [10]. Various new multimodel 
schemes were tested on the Indian region for rainfall forecast [19-21]. On examination of 5-multimodel schemes they realized that the accuracy of the rainfall forecasts can be increased over Indian region. Furthermore, they worked upon probabilistic prediction of the Indian region and found the probabilistic forecasts are superior to multimodel ensemble mean. This group has numerous research works on the prediction of rainfall using various techniques. In midlatitude, the sea level pressure, wind, and rainfall have a strong tie and thus can be used in multiple regression method to downscale the rainfall. In a recent study, canonical correlation analysis is used to downscale rainfall over Indian region and other $[22,23]$. They found some improvements in the forecasts skills over some parts of northeast and peninsular India. There is no strong relationship between rainfall and other variables like sea surface temperature, winds, and outgoing long wave radiation over tropical region. In another study using stepwise regression, Salvi et al. [24] showed that their method could capture the rainfall over mountainous regions of India. They evaluated the future projection of rainfall over Indian region. The group is engaged in the various kinds of downscaling methods for rainfall over Indian region.

In this study, we used liner regression method to downscale the rainfall over the Indian region. It is known that, even in hindcast mode, none of the models provide correct forecast for a range of years. Perhaps, that was one of the necessities of the multimodel based prediction techniques. In a better way postprocessing datasets and statistical techniques can work together to refine the forecast further. Answers on various issues, for example, minimum number of member models to construct superensemble, length of datasets, and other sensitivity issues can be found in Kumar and Krishnamurti [25]. The rainfall product is being improved first by downscaled methodology and then by superensemble method. In some of the studies, the prediction of Indian summer monsoon rainfall is being improved by superensemble and downscale method [25-28]. In the present study, we worked with rainfall anomalies and the skills were compared among the best models (ECMWF model comes out best among 16 suites of models for Indian region, Kumar and Krishnamurti [25]), ensemble mean (EM), and two multimodel schemes. One of the important aspects here we tried to bring out is, how, accurately, can we forecast the extreme events? A new multimodel scheme, based on estimation theory, namely, Best Linear Unbiased Estimator (BLUE), has been examined [29]. Furthermore, this study compares two operational schemes which have been used in hurricane prediction in the Atlantic basin.

The present study illustrates performance of the best model, ensemble mean, synthetic superensemble (SSE) technique, and BLUE scheme on 16 state-of-the-art coupled climate models for 15 summer seasons for the Indian region. This paper deals with the application of multimodel statistical methods. The skill scores used in this work are spatial correlation coefficient, RMSE, chi-square values for measure of association, ETS, BIAS, Heidke Skill Score [30], and ROC (Relative Operating Characteristic [30, 31]). ROC is the plot between true positive rates (here hits score ratio or probability of detection) and false positive rate (here FAR ratio or False Alarm Ratio) for the forecasts. A curve closer towards the $y$-axis indicates more accurate test. Thus, the area under the curve is the measure of the ROC score.

\section{Dataset Used}

Downscaled rainfall datasets (for 15 years, 1987-2001) from sixteen coupled models [33] are included in this study. All the models were integrated from May 1 to September 30 for the summer season (JJAS). Here we analyzed only summer season of monsoon (June to September) datasets in this study. Table 1 contains some details for atmospheric and oceanic components of each model, namely, model name, model resolution, initial conditions for simulation, and numbers of ensemble predictions. The ensemble mean forecasts from a single model's several runs are also included in this study. These model forecasts are cast at a common horizontal resolution of 2.5-degree latitude by 2.5 -degree longitude for the construction of multimodel ensembles. APHRODITE Rainfall [34] dataset was used as observed rainfall. This data is based on thousands of rain gauges over a large region of monsoon Asia. The spatial resolution of the datasets is 0.25 $\times 0.25$ lat-lon grid while the time interval of data is daily to monthly. To interpolate model's data from coarse resolution to fine resolution of observational dataset, we used 4-point Bessel interpolation method.

\section{Downscaling and Multimodel Schemes}

Liner regression scheme is applied for downscaling and to construct downscaled datasets from each member model against APHRODITE Rainfall datasets.

Chakraborty and Krishnamurti [26] have shown the improved rainfall forecasts with downscaling and without downscaling from member models, ensemble mean, and superensemble scheme. They illustrated that the downscaled superensemble scheme shows higher correlation and reduced RMSE over Indian summer monsoon rainfall. During multimodel ensemble, we considered entire duration of datasets of 15 years ( 15 years $\times 4$ months $=60$ values) of monthly rainfall. Next, we constructed multimodel schemes based on downscaled datasets. It is shown that the data of 15 years were sufficient to carry out the downscaling as the coefficients stabilize after 10 years of datasets [25].

We believe that a data processing method improves the model datasets and adds some error as well. However, this can be reduced in some situations. There is a major difference between the mathematical strategy for downscaling and for the construction of the multimodel superensemble scheme. The former downscales each model separately with respect to the observed estimates, whereas the multimodel superensemble calculates a single forecast considering forecasts from the member models all together. It performs a multiple liner regression to remove the collective bias of the suite of models. The two methods are mutually independent. Over all, first downscaling helps in sprouting the regional features in the rainfall forecasts from each member model and then superensemble scheme is improving the forecast 


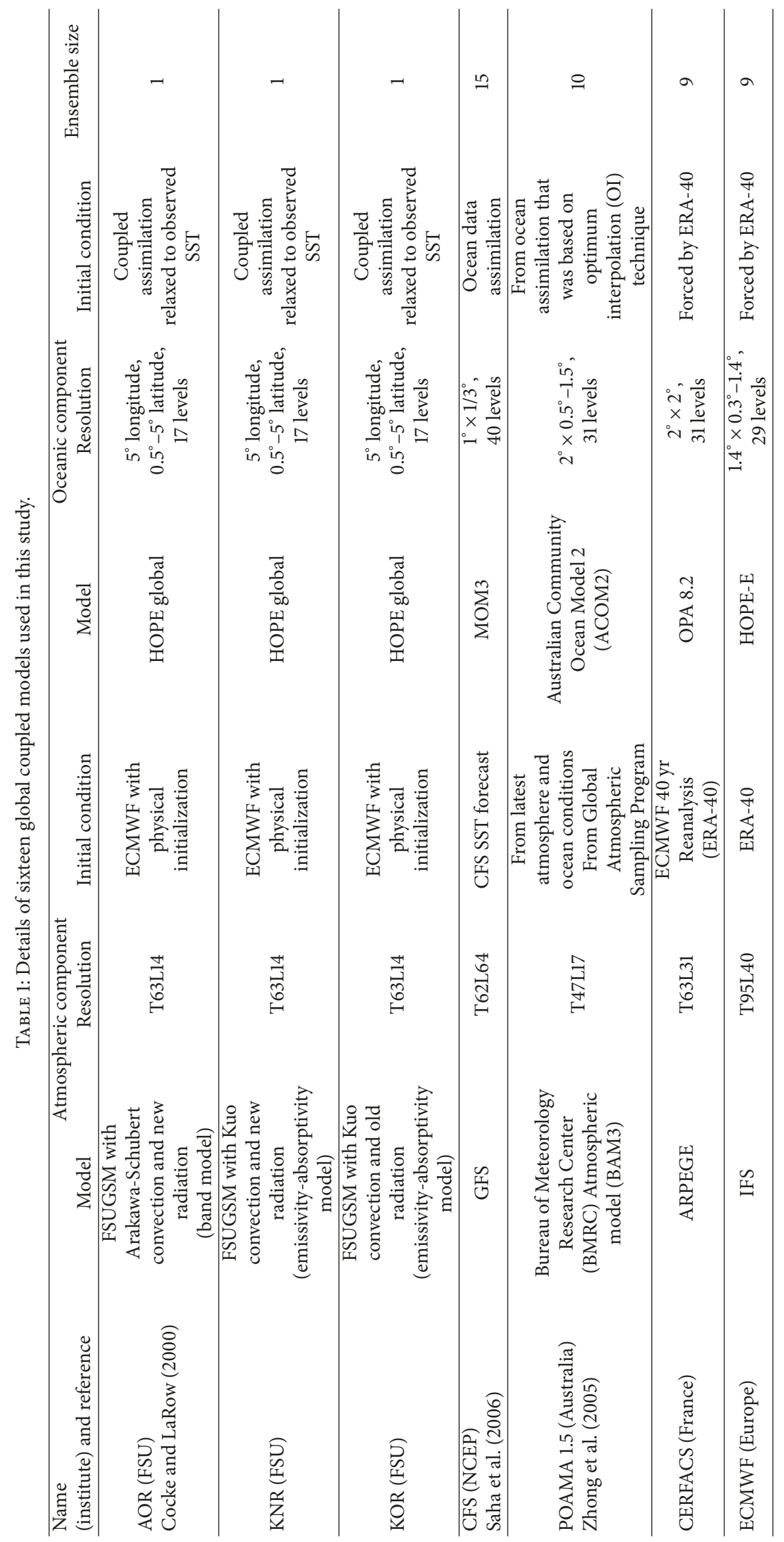




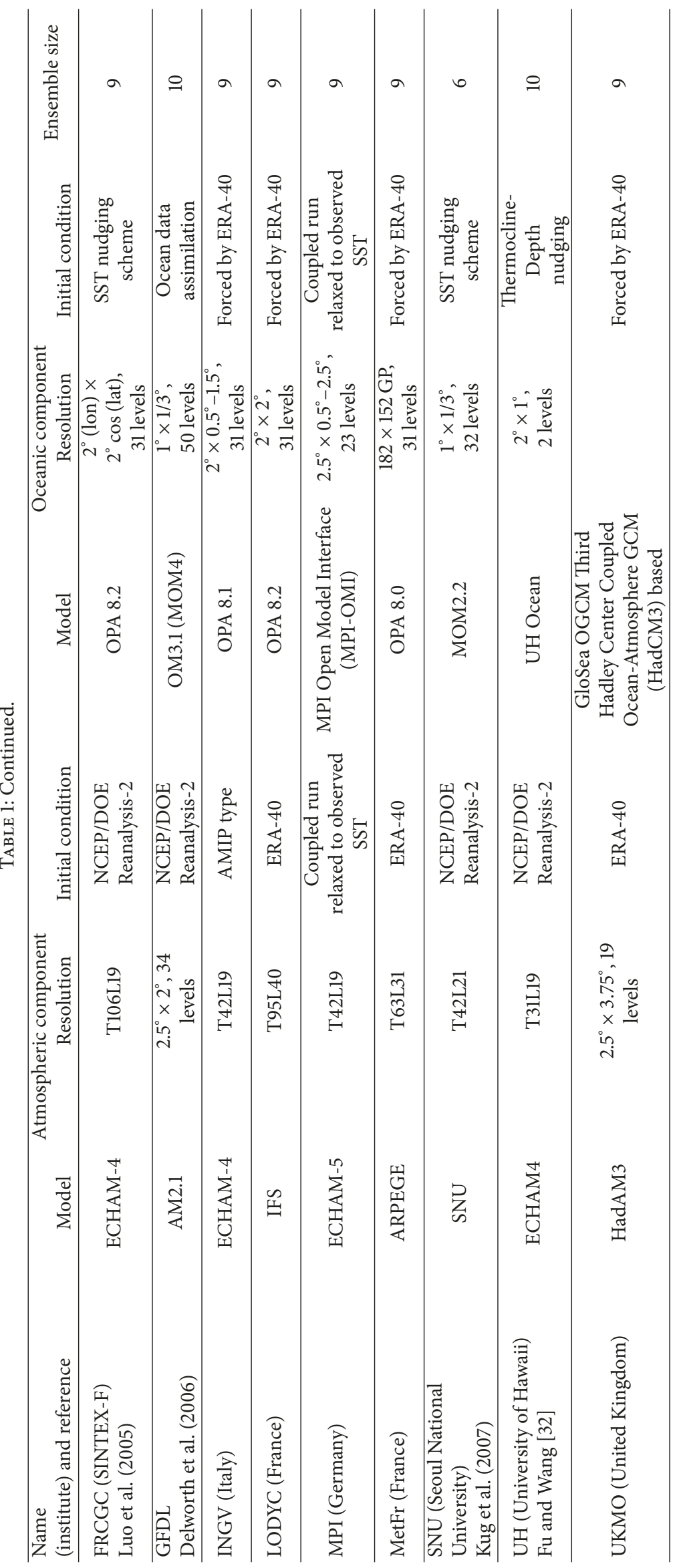


based on multimodel. Cross validation method is used during superensemble and BLUE methodology. In this method, a year, which was forecasted, was not taken, while calculating the downscaling or superensemble weights.

3.1. Downscaled Methodology. APHRODITE Rainfall [34] is used to downscale the rainfall forecast from member models over the Indian region.

$$
R_{\mathrm{obs}}=a R_{\mathrm{mdl}}+b+\varepsilon,
$$

where $R_{\mathrm{obs}}$ and $R_{\mathrm{mdl}}$ are the observed and interpolated model forecasts of rainfall (at the same resolution), respectively; $a$ and $b$ are regression coefficients known as the slope and intercept of the least square fitting; and $\varepsilon$ is the error term.

$$
R_{\mathrm{dscl}}=a R_{\mathrm{mdl}}+b,
$$

where $R_{\mathrm{dscl}}$ is the downscaled rainfall forecast of the model; here $a$ and $b$ are calculated using (2) at each grid point and separately for every month of the year. We left out the year to be downscaled from the calculation to calculate $a$ and $b$ following the method of cross validation. There are many more downscaling methods, for example, canonical analysis and stepwise pattern projection. The linear downscaling methods perform well as compared to other methods [35]. We choose a linear downscaling method here.

3.2. Synthetic Superensemble Technique. The superensemble methodology $[1,36]$ produces a single forecast based on multimodel forecasts. Multimodel superensemble forecasts based on downscaled datasets from member models were constructed as well [37]. We expressed that as follows:

$$
S=\bar{O}+\sum_{i=1}^{N_{\mathrm{mdl}}} w_{i}\left(F_{i}-\bar{F}_{i}\right),
$$

where $S$ is the superensemble prediction, $\bar{O}$ is the observed time mean (climatology), $w_{i}$ are the weights for the individual models $i, F_{i}$ and $\bar{F}_{i}$ are the forecast and forecast mean for a model $i$ for training period, and $N_{\text {mdl }}$ is the number of models. Here weights are obtained by minimizing error using least square method. The sum of the weights needs not be one and they vary from negative values to positive values.

3.3. BLUE Technique. In this study, we introduce another multimodel construction technique based on estimation theory. Individual model is downscaled to sprout the regional features of the rainfall. Next, superensemble scheme and BLUE acted on multimodels to remove the model biases. In case of BLUE the coefficients are inversely proportional to the errors of the models and the sum of coefficients is one. The methodology is described in the Appendix.

\section{The Spatial Variability of Rainfall}

Spatial patterns of rainfall anomalies for 1987, 1991, 1995, and 2000 are being shown in Figure 1. Rainfall anomalies from APHRODITE Rainfall datasets, coupled model from ECMWF, ensemble mean, superensemble scheme, and BLUE are shown in the first, second, third, fourth, and fifth rows, respectively. The rainfall anomalies from APHRODITE, ECMWF model, EM, superensemble scheme, and BLUE captured a range of variability from drought to flood year rainfall over Indian region. Year 1987 was considered as one of the worst droughts in the history of Indian summer monsoonal rainfall variability, which, remotely, had an influence from El-Niño event in Eastern Pacific Ocean. The central Indian region was badly affected by very low rainfall while eastern India received a good rainfall. Rainfall deficient over central India was simulated by most of the models, while the patches of extreme rainfall were not captured by any one. Year 1991 was affected by low rainfall over northern and northeastern India. Interestingly ECMWF captured it fully, as well as superensemble scheme, but EM and BLUE failed here. Year 1995 was witnessed with drought over southcentral India while flood kinds of situations prevailed over northern India. ECMWF model was best to simulate the rainfall variability over the Indian region, but it failed to simulate the rainfall over the eastern parts of India. SSE tried to simulate the rainfall variability but missed deficient rainfall patches over central India. Some of the patches of dry region over Odisha (20.95N, 85.05E) were remarkably captured. It is to be noted that BLUE did better than other models in case of year 2000, which was almost a monsoon drought (rainfall was $-9 \%$ of the climatological normal) over Indian region. Tables 2 and 3 show the year by year spatial correlation and RMSE numbers for all the member models, EM, superensemble scheme, and BLUE. From Tables 2 and 3, we found that the correlation varies from -0.31 to 0.59 for all the models. The ranges of correlation coefficients are varying from negative to positive values which is why we cannot talk about significance of the correlations. For some of the years (e.g., 1991, 1995) the correlation has significance of 0.02 (two-tailed probabilities).

It may be noted that the highest correlation for a year varies from model to model, yet multimodel schemes (BLUE and superensemble) perform better than any member model and EM. We observe that for the year 1999 none of the models and schemes has a positive correlation except CERF, KORAM, MAXP, and NCEP. Table 2 has the RMSE range from 1.34 to 3.82. Here multimodel schemes tried to minimize the RMSE but the margin between them and member models are not so much. It may be mentioned that rainfall variability over Sri Lanka was very well captured by superensemble (correlation coefficient $(\mathrm{CC})=0.44$ ). The skills of rainfall variability from year to year are explained in Figures 2(a) and 2(b) in terms of spatial correlation coefficient and RMSE. BLUE and EM keep their spatial correlation coefficient positive for most of the time except for 1999. In Figure 2, we considered the target region slightly smaller than the bigger region displayed in Figure 1, because many of the northern regions especially north of $30 \mathrm{~N}$ are rain gauges sparse. Chakraborty and Krishnamurti [38] found the negative anomaly correlation for year 1999 for a bigger monsoon region. In case of ECMWF and superensemble scheme spatial correlation is not higher for all years. It is varying from positive to negative from 0.5 to -0.24 . Figure 2 (b) shows RMSE, which is lowest in case of BLUE. Here superensemble scheme comes out distinct in many years with lowest RMSE. 


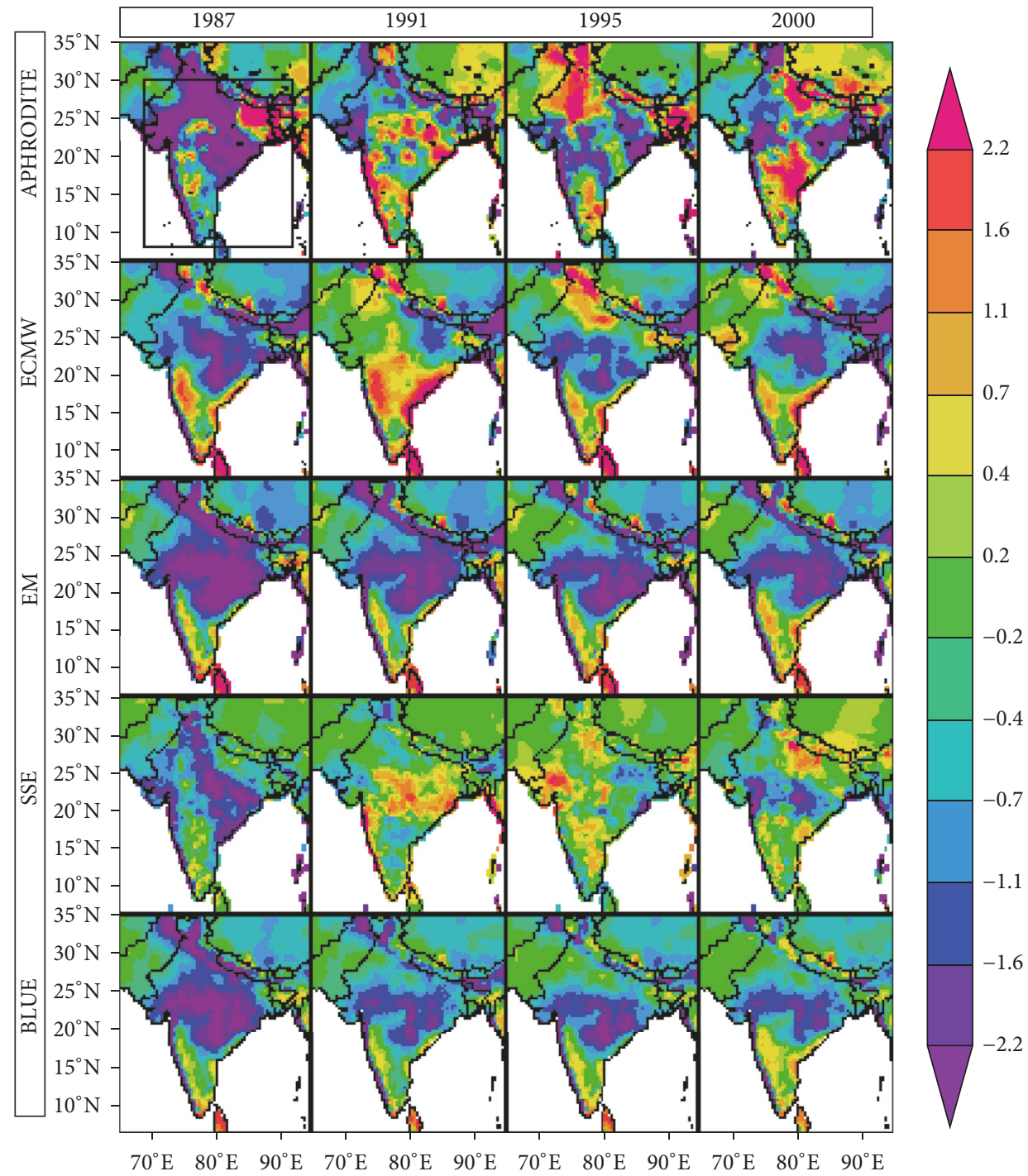

FIGURE 1: June to September rainfall anomalies (mm/day) for 1987, 1991, 1995, and 2000 from APHRODITE, ECMWF (abbreviated in caption as ECMW), EM, SE, and BLUE. A rectangular box (69-92E, 8-30) is shown in the first panel (top right corner). This is the target region of Figures 2 and 3.

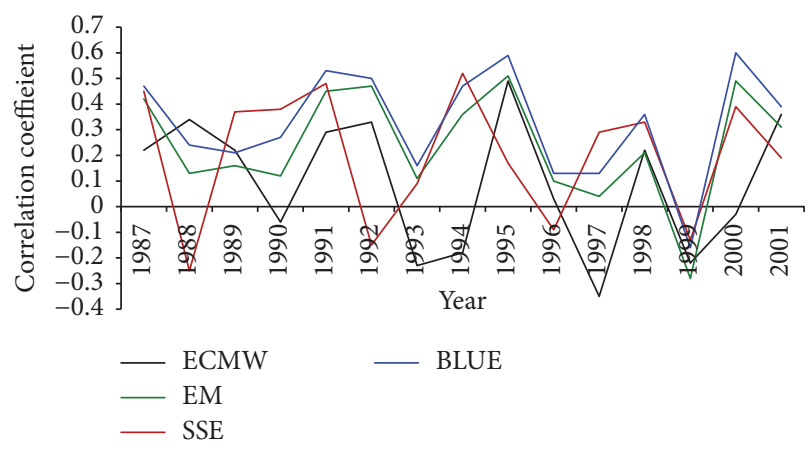

(a)

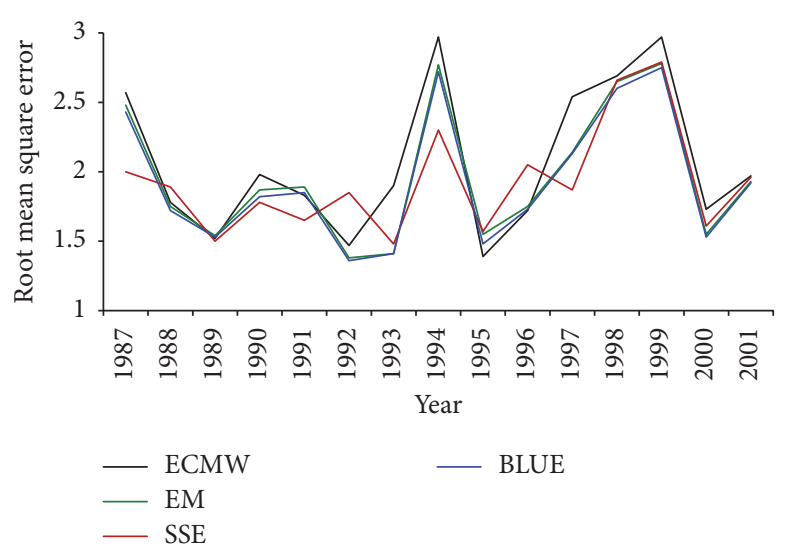

(b)

FIGURE 2: (a) CC and (b) RMSE for ECMWF, EM, superensemble scheme, and BLUE for JJAS seasonal rainfall anomaly predictions. Area averaged over Indian region (69-92E, 8-30N). 


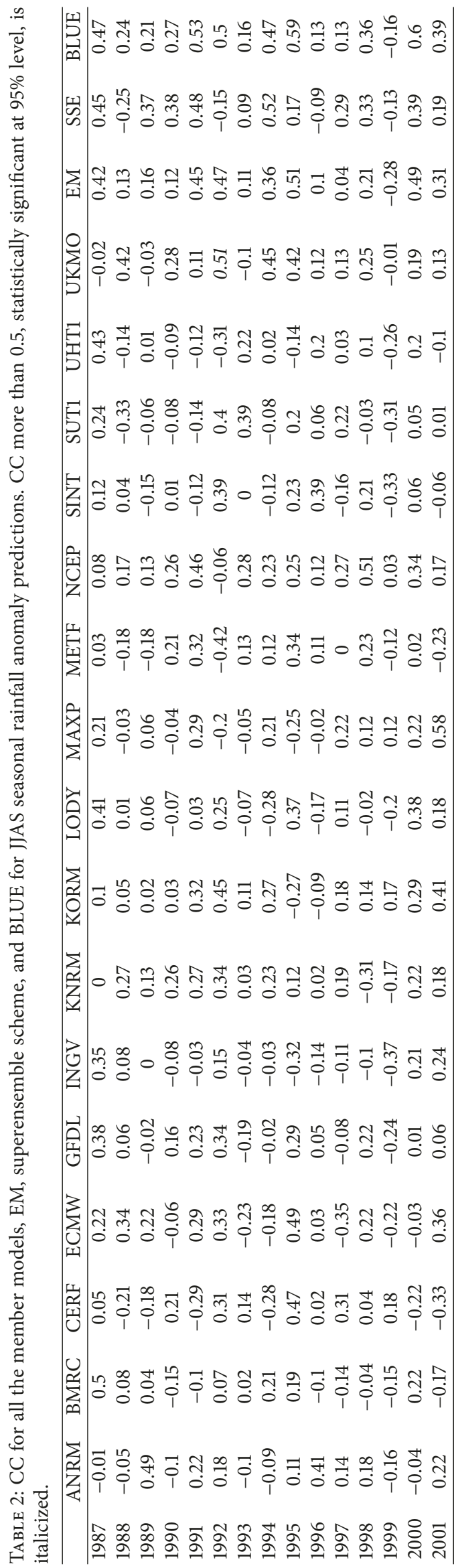




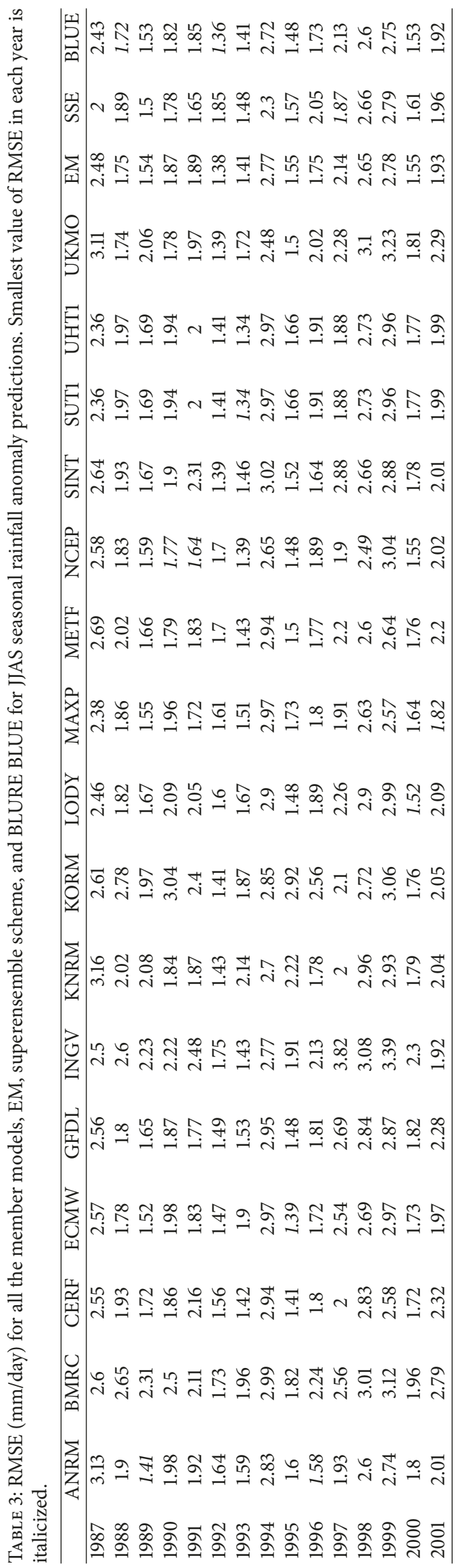




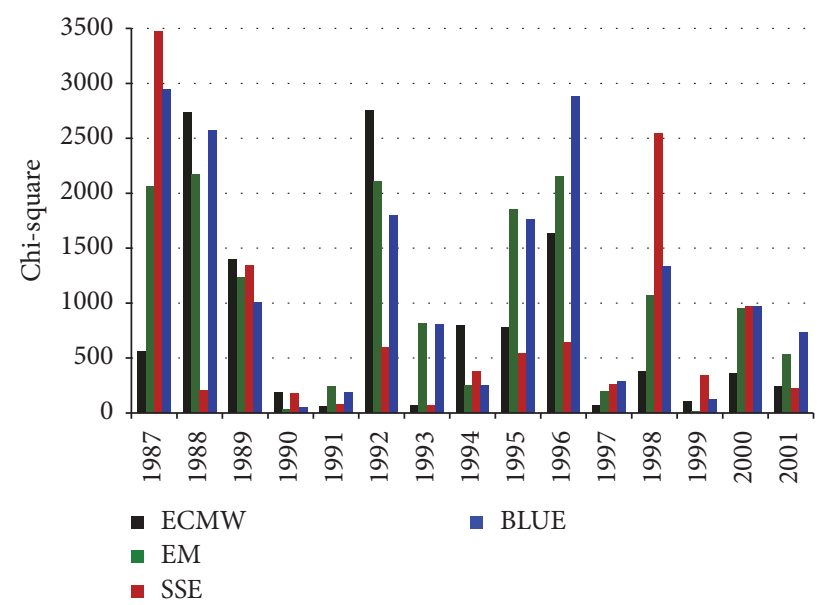

FIGURE 3: $\chi^{2}$ values for measuring association between observed rainfall and rainfall over Indian region $(69-92 \mathrm{E}, 8-30 \mathrm{~N})$ from ECMWF, EM, superensemble scheme, and BLUE for JJAS seasonal rainfall anomaly predictions for threshold of $-1 \mathrm{~mm} /$ day.

It is interesting to note that BLUE is almost following the EM. Furthermore, in case of year 1995 all the models have lowest RMSE and highest correlation, while for the year 1999 RMSE reached the highest value and correlation became lowest.

In this study, we also used measure of association of attributes to judge the extent of closeness between a model forecast and observed rainfall. Qualitative variables whose outcomes are expressed as "yes" or "no" or by some categories, namely, "Good" or "Bad," are referred to as attributes in the statistics literature. whether two attributes are associated or not is tested using the chi-square test of independence.

Figure 3 displays the chi-square values for comparing association between observed and different model forecasts for domain under study. It is based on every grid point over India. The target region is India $(69-92 \mathrm{E}, 8-30 \mathrm{~N})$. BLUE is showing highest categorical association for 1996, 1997, 2000, and 2001, while superensemble scheme shows highest categorical association for 1987, 1990, 1998, and 1999. Next ECMWF shows highest categorical association for 1988, 1989, 1992, and 1994, while EM comes out with highest association for 1991, 1993, and 1995. Both BLUE and superensemble scheme are doing well with respect to this measure. One contingency table, Table 3, is provided for year 1987 for the threshold of -0.1 rainfall anomalies for BLUE. This table has a significance to calculate the skill scores for the categorical rainfall. ETS and BIAS were calculated for rainfall anomalies for the threshold of -3 to $3 \mathrm{~mm} /$ day (Figures $4(\mathrm{a})$ and $4(\mathrm{~b})$ ) for the Indian region (lon $=69.0$, lon $=92.0 \mathrm{E}$; lat $=8.0$, lat $=30.0 \mathrm{~N})$. Interestingly, BLUE is commanding for negative threshold while superensemble scheme is commanding for all positive rainfall thresholds for 15 years of period. BLUE had ETS range between 0 and 0.28 , while superensemble scheme had ETS range from 0.04 to 0.18 . That indicates BLUE has remarkable potential to predict droughts. An ETS of 0.3 is considered a good one in case of rainfall [38]. For the various categories of rainfall (light, moderate, and heavy rains) Dash et al. [39] get ETS values of 0.24 to 0.03 over
TABLE 4: Contingency table for year 1987 corresponding to the rainfall anomaly threshold of $-0.1 \mathrm{~mm} /$ day for BLUE.

\begin{tabular}{lccc}
\hline & \multicolumn{3}{c}{ Prediction } \\
& Yes & No & Total \\
\hline Observation & & & \\
Yes & $2894^{\mathrm{a}}$ & $1913^{\mathrm{b}}$ & 4807 \\
No & $1690^{\mathrm{c}}$ & $8543^{\mathrm{d}}$ & 10233 \\
Total & 4584 & 10456 & 15040 \\
\hline
\end{tabular}

${ }^{\mathrm{a}}$ Hits. ${ }^{\mathrm{b}}$ Misses. ${ }^{\mathrm{c}}$ False alarm. ${ }^{\mathrm{d}}$ Correct negatives.

the Indian region. Next in case of BIAS (Figure 4(b)) BLUE shows least BIAS for positive thresholds while superensemble scheme shows least BIAS for negative thresholds. BLUE has the range of BIAS from 0.1 to 1.67 while superensemble scheme has 0.1 to 0.4 . ECMWF and EM are not performing well with BIAS as compared to multimodel schemes. Some of the incompatibility has been discussed regarding ETS while scoring about extreme events [40].

Heidke Skill Score (HSS) has been presented for various years (Figure 5) including flood and drought years of Indian summer monsoon. BLUE is doing better for 1995 and 1998, while superensemble scheme does better for 1988 and 1989. Still, their response becomes mixed if we pin down their superiorities for all the thresholds. For example, in 1995, BLUE does well with ETS for the threshold range of -3 to 1.5 but skill degraded for 1.5 to 3 . In case of 1988 superensemble scheme does good for -0.5 to 3 but stumbled for -3 to -1 thresholds. Overall, these two multimodel schemes come out finer and doing better for all the threshold and years except for few. Hogan et al. [40] recommended HSS over ETS to express skill from multimodels. In Table 4, we explained the numbers of hits, misses, false alarm, and correct negatives for year 1987. It is same as Table 5, but for a year with values.

Rainfall over Indian region shows high rainfall variability, due to large variations in orographic lands, vegetation cover, and soil texture. Probabilistic forecasts are based on the yes/no proposition. Over a grid, for a threshold, this yes/no proposition decides the hits (both observation and model show nonzero rainfall values), misses (where observation shows nonzero while model shows zero rainfall values), and false alarm (where observation shows zero while model shows nonzero rainfall values) as basic variables for the probabilistic forecasts. Figure 6 shows the ROC plots between hit ratio and false ratio for JJAS seasonal rainfall anomalies, for four years. If the ROC curve for a model is far away from the 45-degree line that model performs better than others. The pink dotted line indicates exact matches of the observed and forecast cases, that is, ideal forecast cases. For 1998 BLUE comes out as the best one while for 2000 superensemble comes out as the best. For the two remaining years 1987 and 1998 their responses are mixed. Acharya et al. [41] showed results for three categories of rainfall from multimodel schemes over Indian region. They found better skills of ROC for the wet and dry years as compared to normal monsoon years. 


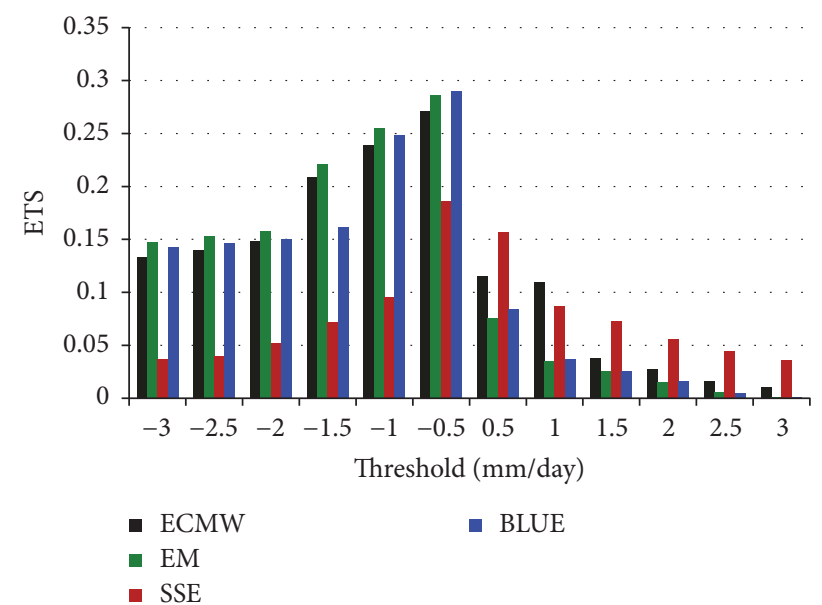

(a)

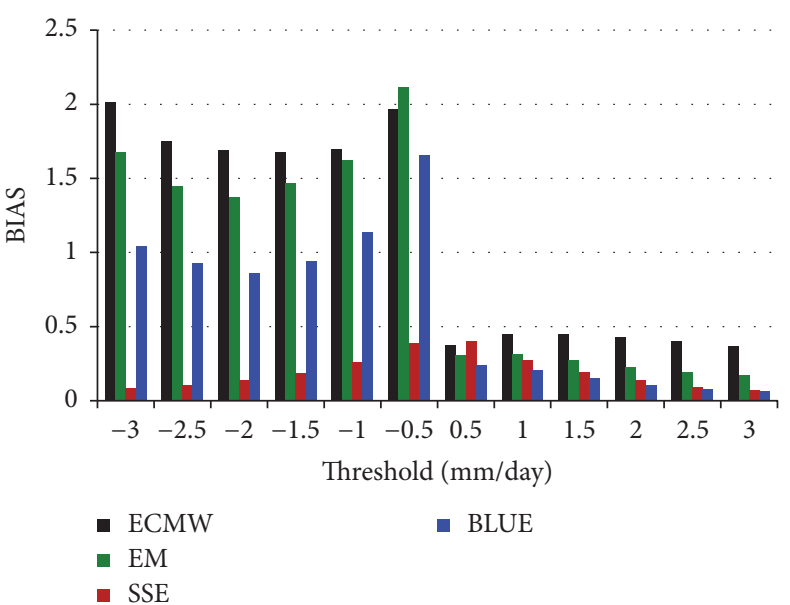

(b)

FIGURE 4: (a) ETS and (b) BIAS for ECMWF, EM, superensemble scheme, and BLUE for JJAS seasonal rainfall anomaly predictions for Indian region.
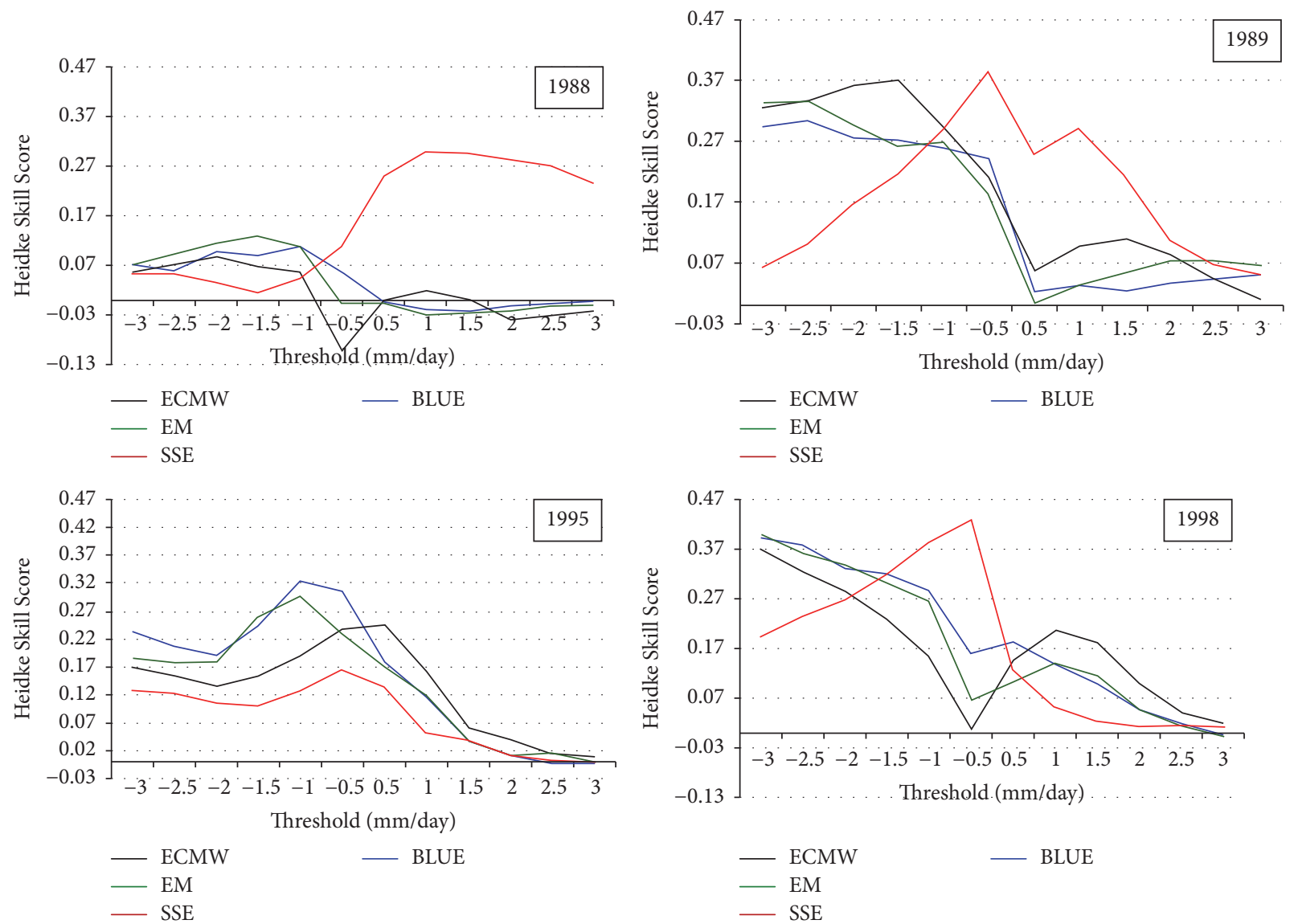

Figure 5: Heidke Skill Score plots for ECMWF, EM, superensemble scheme, and BLUE for JJAS seasonal rainfall anomaly predictions for many years over Indian region.

\section{Conclusions and Discussion}

All the results based on commonly used skill metrics are performed on downscaled datasets for 15 years (1987-2001), 16 member models, and observed rainfall datasets from
APHRODTE. Year by year, the superiority of four models has been cited based on chi-square which indicates the dependency of model on skill matrix. The maximum values of correlation coefficient obtained from the multimodel schemes EM, SSE, and BLUE are -0.28 to $0.51,-0.16$ to 
TABLE 5

\begin{tabular}{lccc}
\hline & & Model & Total \\
\hline Observed & & No & \\
Yes & $\mathrm{a}$ (hits) & $\mathrm{b}$ (misses) & $\mathrm{a}+\mathrm{b}$ (observed yes) \\
No & $\mathrm{c}$ (false alarms) & $\mathrm{d}$ (correct negatives) & $\mathrm{c}+\mathrm{d}$ (observed no) \\
Total & $\mathrm{a}+\mathrm{c}$ (forecast yes) & $\mathrm{b}+\mathrm{d}$ (forecast no) & $n=\mathrm{a}+\mathrm{b}+\mathrm{c}+\mathrm{d}$ (total) \\
\hline
\end{tabular}
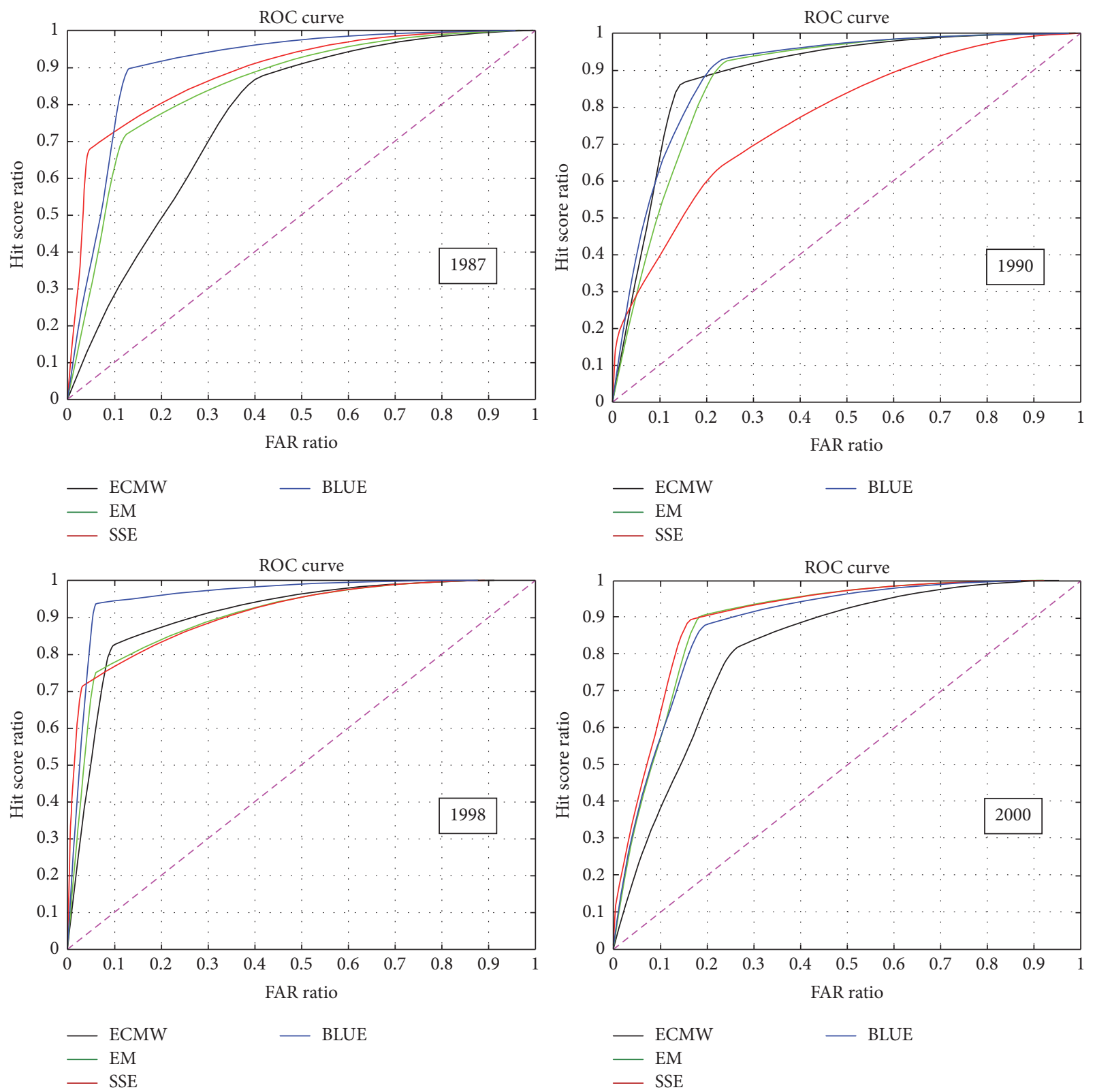

FIGURE 6: ROC plots for ECMWF, EM, superensemble scheme, and BLUE for JJAS seasonal rainfall anomaly predictions over Indian region.

0.59 , and -0.25 to 0.52 . On the other hand, ECMWF has the range from -0.35 to 0.49 only. Clearly the improvement is not much, but for rainfall anomalies, surely it is appreciable. While, in case of RMSE, EM has a range from 1.41 to 2.78, SSE has the range from 1.48 to 2.79 and BLUE has the range from
1.36 to 2.75 . Categorical association attained by ECMWF is 0.39 , EM is 0.42 , SSE is 0.48 , and BLUE is 0.45 . In case of ETS, ECMWF attained 0.27. The ETS for EM is 0.28 , SSE is 0.18 , and BLUE is 0.29 . BIAS is reduced to 0.35 in case of ECMWF, 0.15 for EM, and 0.05 for SSE and BLUE. 
Overall SSE and BLUE improved on best model (ECMWF) and ensemble mean (EM) on the metrics skill used in this study for the Indian region. Sometime BLUE does better than superensemble scheme and sometime superensemble scheme does better than BLUE method. It is worth mentioning that the BLUE methodology has the simplicity in computing model weights for constructing the multimodel forecast. So, this method can be explored more for other events as well. One of the challenges is the prediction of rainfall anomalies (e.g., extreme events of floods).

Multiple regression schemes can be applied to improve the rainfall forecasts, as the performance of the GCM are very poor for rainfall forecasts. In the multiple regressions, one can use winds, temperature, geopotential height, and specific humidity to predict rainfall. Some of the studies have shown the use of other variable, for example, SST and OLR for downscaling the rainfall. Somehow, linear regression is a crude method while canonical correlation analysis and stepwise pattern projection methods are considered an advanced one for downscaling. Furthermore, other sophisticated methods like statistical-dynamical Kalman Filter method [42], hyperensemble method [43], and Artificial Neural Network method can be used for multimodel ensemble prediction of rainfall in our next study.

\section{Appendix}

The data are expressed in $2 \times 2$ contingency table as shown in Table 5.

Thus the Chi-square statistics is given by

$$
\chi^{2}=\frac{n(a d-b c)^{2}}{(a+c)(b+d)(a+b)(c+d)} .
$$

This follows chi-square distribution with 1 degree of freedom [44].

Comparing the two contingency tables for two different models the chi-square value gives the guidance about the strength of the relationship between observed and model forecast values. The larger chi-square value indicates a stronger relationship. Here we are getting different categories corresponding to different threshold values of rainfall anomalies.

If $T_{1}, T_{2}, \ldots, T_{k}$ are $k$ unbiased independent estimators of the parameter $\mu$ and variances $\sigma_{i}^{2}$ then $T=\sum_{i=1}^{k} \alpha_{i} T_{i}$ will be the Best Linear Unbiased Estimator of $\mu$, if

$$
\alpha_{i}=\frac{1 / \sigma_{i}^{2}}{\sum_{i=1}^{k}\left(1 / \sigma_{i}^{2}\right)}, \quad i=1,2, \ldots, k
$$

Proof. Since $T_{i}$ 's are unbiased we have

$$
\begin{gathered}
E\left(T_{i}\right)=\mu \quad \forall i=1,2, \ldots, k, \\
\operatorname{var}\left(T_{i}\right)=\sigma_{i}^{2} \quad \text { for } i=1,2, \ldots, k
\end{gathered}
$$

and due to independence

$$
\operatorname{cov}\left(T_{i}, T_{j}\right)=0 \quad \forall i \neq j .
$$

We consider

$$
T=\sum_{i=1}^{k} \alpha_{i} T_{i}
$$

as the estimator of $\mu$ such that

$$
E(T)=\mu .
$$

Clearly, $T$ will be unbiased for $\mu$ if

$$
\sum_{i=1}^{k} \alpha_{i}=1
$$

Now,

$$
\operatorname{var}(T)=\sum_{i=1}^{k} \alpha_{i}^{2} \sigma_{i}^{2}
$$

Since $T_{i}$ 's are independent, we are in search of $\alpha_{i}$ 's such that $\operatorname{var}(T)$ is minimum.

Define

$$
w=\operatorname{var}(T)-2 \varphi\left(\sum_{i=1}^{k} \alpha_{i}-1\right),
$$

where $\varphi$ is Lagrange's multiplier.

Taking partial derivative of $w$ with respect to $\alpha_{i}$ and equating it to zero for minimizing $w$ subject to condition (A.7) we have

$$
\varphi=\frac{1}{\sum_{i=1}^{k} 1 / \sigma_{i}^{2}} .
$$

This leads to

$$
\alpha_{i}=\frac{1 / \sigma_{i}^{2}}{\sum_{i=1}^{k} 1 / \sigma_{i}^{2}} .
$$

We propose estimating $\sigma_{i}^{2}$ from the past performances of the model $i$ and using $\alpha_{i}$ to find out $T$, the multimodel output comprising $k$ models. $T$ would be an optimum multimodel output [29].

$$
\begin{aligned}
\mathrm{BIAS} & =\left[\frac{1}{M} \sum_{m=1}^{M}\left(f_{m}-O_{m}\right)\right] \\
\mathrm{ETS} & =\frac{H-(F x(O / M))}{F+O-H-(F x(O / M))}
\end{aligned}
$$

Here,

$M$ is number of grid points, $f_{m}$ is forecast value at grid point $m$, $O_{m}$ is observed value at grid point $m$, $F$ is area where event is forecasted, 
$O$ is area where event is observed,

$H$ is area where $F$ and $O$ overlap, the hit area.

Based on the contingency table, Table 5, HSS (Wilks 2012) can be defined as

Heidke Skill Score (HSS)

$$
=\frac{(\text { hits }+ \text { correct negatives })-(\text { expected correct })_{\text {random }}}{N-(\text { expected correct })_{\text {random }}},
$$

where

$$
\begin{aligned}
& \text { (expected correct })_{\text {random }} \\
& =\frac{1}{N}[(\text { hits }+ \text { misses })(\text { hits }+ \text { false alarms }) \\
& +(\text { correct negatives }+ \text { false alarms })]
\end{aligned}
$$

\section{Acronyms for Models, Institutes, or Other Names}

$\begin{array}{ll}\text { APHRODITE: } & \text { Asian Precipitation-Highly Resolved } \\ & \text { Observational Data Integration Towards } \\ & \text { Evaluation of Water Resources } \\ \text { BLUE: } & \text { Best Linear Unbiased Estimator } \\ \text { CERFACS: } & \text { Centre Européen de Recherche et de } \\ & \text { Formation Avancée en Calcul Scientifique, } \\ & \text { France } \\ \text { FSU: } & \text { Florida State University } \\ \text { ECMWF: } & \text { European Center for Medium Range } \\ & \text { Weather Forecasting, UK } \\ \text { EM: } & \text { Ensemble mean } \\ \text { ETS: } & \text { Equitable threat score } \\ \text { GPM: } & \text { Global Precipitation Measurement } \\ \text { JJAS: } & \text { June, July, August, and September } \\ \text { KOR: } & \text { FSU coupled model where Kuo convection } \\ & \text { and old radiation (emissivity-absorptivity } \\ & \text { model) schemes are used } \\ \text { MAXP: } & \text { MAX-Planck Institut für Meteorologie, } \\ & \text { Germany } \\ \text { NCEP: } & \text { National Center for Environmental } \\ \text { RMSE: } & \text { Prediction, USA } \\ \text { ROC: } & \text { Root Mean Square Error } \\ \text { SSE: } & \text { Relative Operating Characteristic } \\ \text { TRMM: } & \text { Synthetic superensemble } \\ & \text { Tropical Rainfall Measuring Mission. } \\ \end{array}$

\section{Conflicts of Interest}

The authors declare that they have no conflicts of interest.

\section{Acknowledgments}

The authors are thankful to Professor T. N. Krishnamurti for his encouragement and valuable discussions during this work. The authors wish to acknowledge the APCC/CliPAS for providing coupled model datasets.

\section{References}

[1] T. N. Krishnamurti, C. M. Kishtawal, T. E. LaRow et al., "Improved weather and seasonal climate forecasts from multimodel superensemble," Science, vol. 285, no. 5433, pp. 1548$1550,1999$.

[2] W. T. Yun, L. Stefanova, and T. N. Krishnamurti, "Improvement of the multimodel superensemble technique for seasonal forecasts," Journal of Climate, vol. 16, no. 22, pp. 3834-3840, 2003.

[3] D. Cane and M. Milelli, "Weather forecasts obtained with a multimodel superensemble technique in a complex orography region," Meteorologische Zeitschrift, vol. 15, no. 2, pp. 207-214, 2006.

[4] D. Cane and M. Milelli, "Multimodel SuperEnsemble technique for quantitative precipitation forecasts in Piemonte region," Natural Hazards and Earth System Sciences, vol. 10, no. 2, pp. 265-273, 2010.

[5] B. Johnson, V. Kumar, and T. N. Krishnamurti, "Rainfall anomaly prediction using statistical downscaling in a multimodel superensemble over tropical South America," Climate Dynamics, vol. 43, no. 7-8, pp. 1731-1752, 2013.

[6] L. E. Hay and M. P. Clark, "Use of statistically and dynamically downscaled atmospheric model output for hydrologic simulations in three mountainous basins in the western United States," Journal of Hydrology, vol. 282, no. 1-4, pp. 56-75, 2003.

[7] T. Sato and Y. Xue, "Validating a regional climate model's downscaling ability for East Asian summer monsoonal interannual variability," Climate Dynamics, vol. 41, no. 9-10, pp. 2411-2426, 2013.

[8] S.-Y. Hong and M. Kanamitsu, "Dynamical downscaling: fundamental issues from an NWP point of view and recommendations," Asia-Pacific Journal of Atmospheric Sciences, vol. 50, no. 1, pp. 83-104, 2014.

[9] S. Kang, J. Hur, and J.-B. Ahn, "Statistical downscaling methods based on APCC multi-model ensemble for seasonal prediction over South Korea," International Journal of Climatology, vol. 34, no. 14, pp. 3801-3810, 2014.

[10] S. Gadgil, M. Rajeevan, and R. Nanjundiah, "Monsoon prediction-why yet another failure?" Current Science, vol. 88, no. 9, pp. 1389-1400, 2005.

[11] C. Brankovic, T. N. Palmer, F. Molteni, S. Tibaldi, and U. Cubasch, "Extended-range predictions with ECMWF models: time-lagged ensemble forecasting," Quarterly Journal of the Royal Meteorological Society, vol. 116, no. 494, pp. 867-912, 1990.

[12] Č. Branković and T. N. Palmer, "Atmospheric seasonal predictability and estimates of ensemble size," Monthly Weather Review, vol. 125, no. 5, pp. 859-874, 1997.

[13] T. N. Palmer, F. J. Doblas-Reyes, R. Hagedorn et al., "DEVELOPMENT of a european multimodel ensemble system for seasonal-to-interannual prediction (DEMETER)," Bulletin of the American Meteorological Society, vol. 85, no. 6, pp. 853-872, 2004.

[14] D. S. Rajeevan Pai and V. Thapliyal, "Predictive relationships between Indian Ocean sea-surface temperatures and Indian Summer Monsoon rainfall," Mausam, vol. 53, pp. 337-348, 2002.

[15] M. Rajeevan, D. S. Pai, S. K. Dikshit, and R. R. Kelkar, "IMD’s new operational models for long-range forecast of southwest monsoon rainfall over India and their verification for 2003," Current Science, vol. 86, no. 3, pp. 422-431, 2004.

[16] M. Rajeevan, D. S. Pai, R. A. Kumar, and B. Lal, "New statistical models for long-range forecasting of southwest monsoon 
rainfall over India," Climate Dynamics, vol. 28, no. 7-8, pp. 813828, 2007.

[17] V. Thapliyal and M. Rajeevan, "Updated operational models for long range forecasts of Indian Summer Monsoon rainfall," Mausam, vol. 54, pp. 495-504, 2003.

[18] R. Nanjundiah, "A Quick-Look Assessment of Forecasts for the Indian Summer Monsoon Rainfall in,” IISc report AS 02, 2009.

[19] N. Acharya, S. C. Kar, M. A. Kulkarni, U. C. Mohanty, and L. N. Sahoo, "Multi-model ensemble schemes for predicting northeast monsoon rainfall over peninsular India," Journal of Earth System Science, vol. 120, no. 5, pp. 795-805, 2011.

[20] M. A. Kulkarni, N. Acharya, S. C. Kar et al., "Probabilistic prediction of Indian summer monsoon rainfall using global climate models," Theoretical and Applied Climatology, vol. 107, no. 3-4, pp. 441-450, 2012.

[21] S. C. Kar, N. Acharya, U. C. Mohanty, and M. A. Kulkarni, "Skill of monthly rainfall forecasts over India using multi-model ensemble schemes," International Journal of Climatology, vol. 32, no. 8, pp. 1271-1286, 2012.

[22] P. Sinha, U. C. Mohanty, S. C. Kar, S. K. Dash, A. W. Robertson, and M. K. Tippett, "Seasonal prediction of the Indian summer monsoon rainfall using canonical correlation analysis of the NCMRWF global model products," International Journal of Climatology, vol. 33, no. 7, pp. 1601-1614, 2013.

[23] A. Busuioc, R. Tomozeiu, and C. Cacciamani, "Statistical downscaling model based on canonical correlation analysis for winter extreme precipitation events in the Emilia-Romagna region," International Journal of Climatology, vol. 28, no. 4, pp. 449-464, 2008.

[24] K. Salvi, S. Kannan, and S. Ghosh, "High-resolution multisite daily rainfall projections in India with statistical downscaling for climate change impacts assessment," Journal of Geophysical Research: Atmospheres, vol. 118, no. 9, pp. 3557-3578, 2013.

[25] V. Kumar and T. N. Krishnamurti, "Improved seasonal precipitation forecasts for the Asian monsoon using 16 atmosphereocean coupled models. Part I: climatology," Journal of Climate, vol. 25, no. 1, pp. 39-64, 2012.

[26] A. Chakraborty and T. N. Krishnamurti, "Improving global model precipitation forecasts over India using downscaling and the FSU superensemble. Part II: seasonal climate," Monthly Weather Review, vol. 137, no. 9, pp. 2736-2757, 2009.

[27] T. N. Krishnamurti, A. K. Mishra, A. Chakraborty, and M. Rajeevan, "Improving global model precipitation forecasts over India using downscaling and the FSU superensemble. Part I: 1-5-day forecasts," Monthly Weather Review, vol. 137, no. 9, pp. 2713-2735, 2009.

[28] T. N. Krishnamurti and V. Kumar, "Improved seasonal precipitation forecasts for the Asian monsoon using 16 atmosphereocean coupled models. Part II: anomaly, Journal of Climate, vol. 25, no. 1, pp. 65-88, 2012.

[29] E. L. Lehmann and G. Casella, Theory of Point Estimation, Springer, Second edition, 1998.

[30] D. S. Wilks, "Statistical methods in the atmospheric sciences," in Proceedings of the International Geophysics Series, vol. 100, p. 676, 2011.

[31] I. T. Jolliffe and D. B. Stephenson, Forecast Verification: A Practitioner's Guide in Atmospheric Science, John Wiley Sons, Ltd, 2003.

[32] X. Fu and B. Wang, "The boreal-summer intraseasonal oscillations simulated in a hybrid coupled atmosphere-ocean model," Monthly Weather Review, vol. 132, no. 11, pp. 2628-2649, 2004.
[33] B. Wang, J.-Y. Lee, I.-S. Kang et al., "Advance and prospect of seasonal prediction: assessment of the APCC/CliPAS 14model ensemble retroperspective seasonal prediction," Climate Dynamics, vol. 33, pp. 93-117, 2009.

[34] A. Yatagai, O. Arakawa, K. Kamiguchi, H. Kawamoto, M. I. Nodzu, and A. Hamada, "A 44-year daily gridded precipitation dataset for Asia based on a dense network of rain gauges," SOLA, vol. 5, pp. 137-140, 2009.

[35] M. K. Goyal and C. S. Ojha, "Evaluation of various linear regression methods for downscaling of mean monthly precipitation in arid pichola watershed," Natural Resources, vol. 01, no. 01, pp. 11-18, 2010.

[36] T. N. Krishnamurti, C. M. Kishtawal, D. W. Shin, and C. E. Williford, "Improving tropical precipitation forecasts from a multianalysis superensemble," Journal of Climate, vol. 13, no. 23, pp. 4217-4227, 2000.

[37] T. N. Krishnamurti, A. Chakraborty, R. Krishnamurti, W. K. Dewar, and C. A. Clayson, "Seasonal prediction of sea surface temperature anomalies using a suite of 13 coupled atmosphereocean models," Journal of Climate, vol. 19, no. 23, pp. 6069-6088, 2006.

[38] A. Chakraborty and T. N. Krishnamurti, "Improved seasonal climate forecasts of the south Asian summer monsoon using a suite of 13 coupled ocean-atmosphere models," Monthly Weather Review, vol. 134, no. 6, pp. 1697-1721, 2006.

[39] S. K. Dash, K. C. Pattnayak, S. K. Panda, D. Vaddi, and A. Mamgain, "Impact of domain size on the simulation of Indian summer monsoon in RegCM4 using mixed convection scheme and driven by HadGEM2," Climate Dynamics, vol. 44, pp. 961975, 2015.

[40] R. J. Hogan, C. A. T. Ferro, I. T. Jolliffe, and D. B. Stephenson, "Equitability revisited: why the 'equitable threat score' is not equitable," Weather and Forecasting, vol. 25, no. 2, pp. 710-726, 2010.

[41] N. Acharya, U. C. Mohanty, and L. Sahoo, "Probabilistic multimodel ensemble prediction of Indian summer monsoon rainfall using general circulation models: a non-parametric approach," Comptes Rendus-Geoscience, vol. 345, no. 3, pp. 126-135, 2013.

[42] C. He, X. Zhi, Q. You, B. Song, and K. Fraedrich, "Multi-model ensemble forecasts of tropical cyclones in 2010 and 2011 based on the Kalman Filter method," Meteorology and Atmospheric Physics, vol. 127, no. 4, pp. 467-479, 2015.

[43] L. Vandenbulcke, J. Beckers, F. Lenartz et al., "Super-ensemble techniques: application to surface drift prediction," Progress in Oceanography, vol. 82, no. 3, pp. 149-167, 2009.

[44] M. G. Kendall and A. Stuart, The Advanced Theory of Statistics. Vol. 2, International Statistical Institute, New York, USA, 1961. 

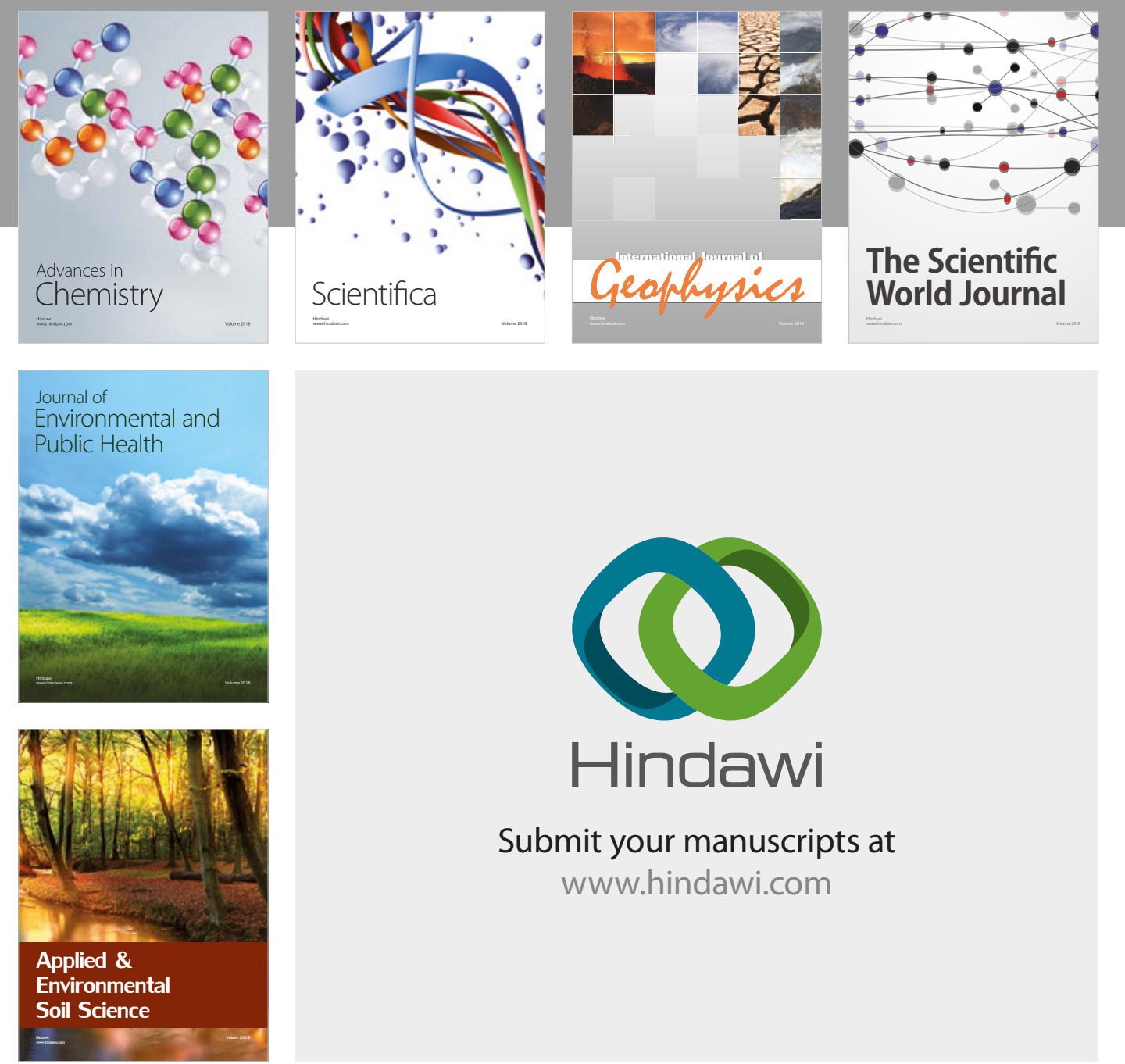

The Scientific

\section{World Journal}
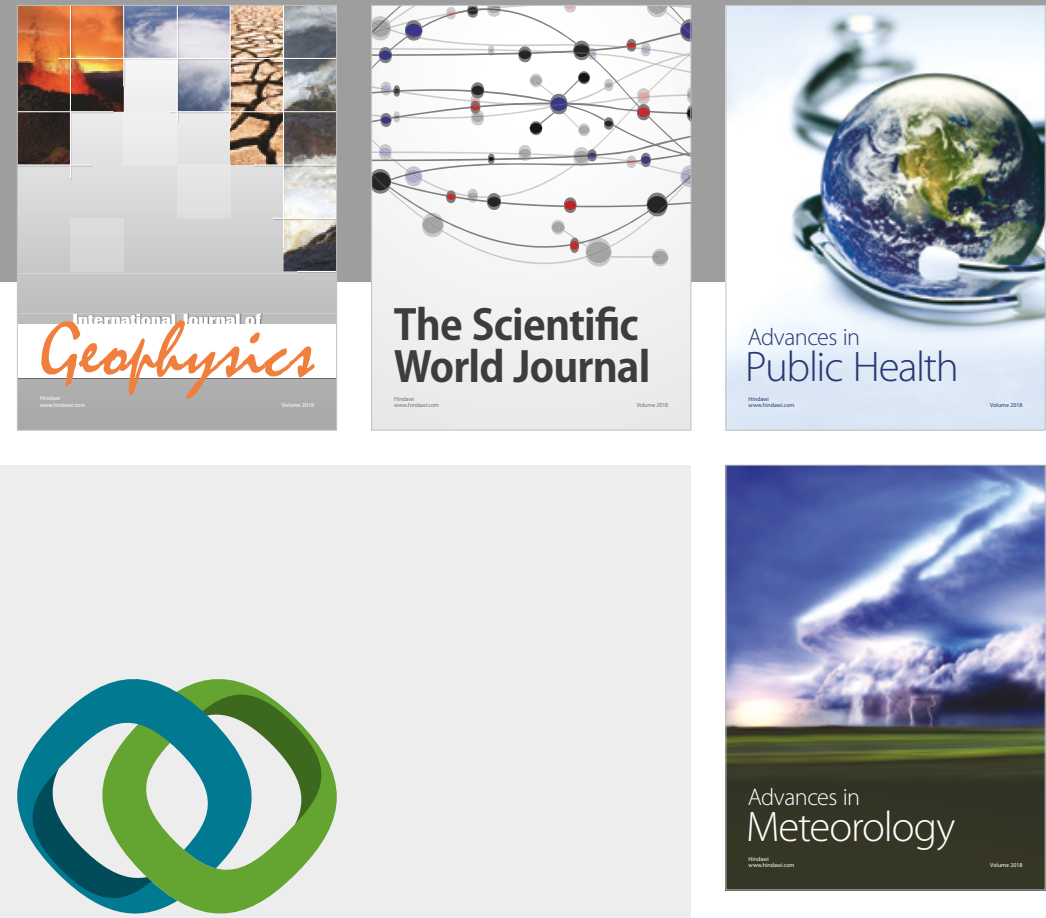

Advan

Public Health

\section{Hindawi}

Submit your manuscripts at

www.hindawi.com
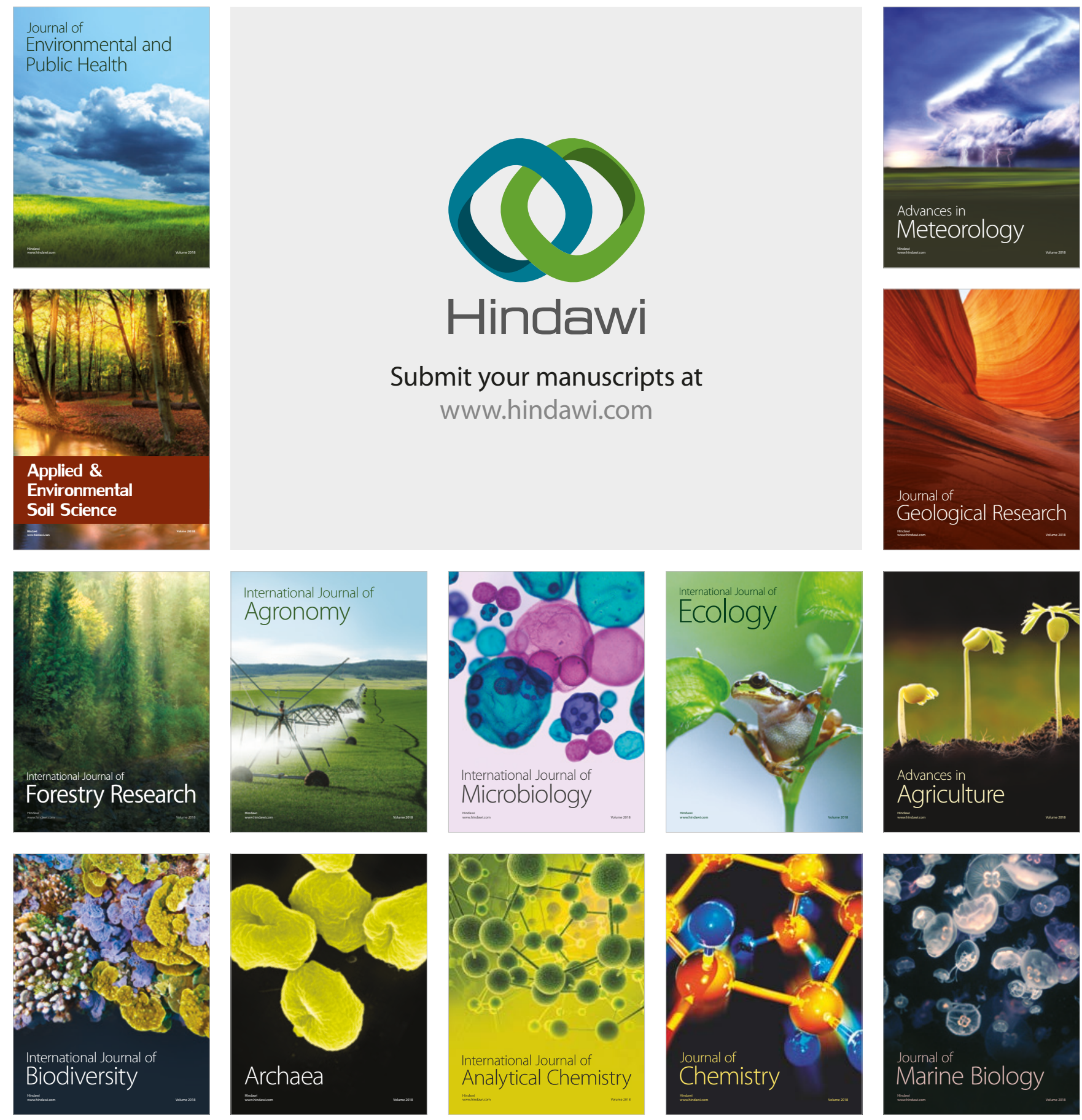